\title{
Desain Pembelajaran Materi Perkalian Menggunakan Konteks Lomba Lari Estafet Di Kelas II
}

\author{
Sunedi \\ Fakultas Keguruan dan Ilmu Pendidikan, Universitas PGRI Palembang \\ Jl. Jend. A. Yani. Lrg. Gotoroyong 13 Ulu, Indonesia \\ sunedi.sudarman@gmail.com
}

\begin{abstract}
This study aims to determine students' understanding of concepts in the context of the material multiplication using a relay race as the starting point of learning and generate learning multiplication trajectory evolving from informal stages to formal stages in class II SD. The method used in this research design (design research) that design learning multiplication using the context of the relay race through the stages of the experiment (preparing for the experiment). Eperimental design (design of experiment) and analysis retropektif (retrospective analysis). Subjects who do are 32 students of SDN 249 Palembang. The activities conducted in this study starts from the activities of a relay race, the baton made of colored paper material, and a jump with a distance of 0 and 1 on the number line. The results of this study indicate that the context of a relay race can support students' understanding of the concept of multiplication. The activities of the student learning to produce student learing trajectory has an important role in understanding the concept of multiplication from the informal to the formal stage.
\end{abstract}

Keywords: Design research, multiplication, relay race.

\section{Abstrak.}

Penelitian ini bertujuan untuk menghasilkan lintasan belajar yang dapat membantu siswa untuk memahami konsep perkalian yang berkembang dari tahap informal ketahap formal di kelas II. Metode yang digunakan dalam penelitian ini adalah penelitian desain riset (design research) yang mendesain pembelajaran perkalian menggunakan konteks lomba lari estafet melalui tahap-tahap percobaan (preparing for the experiment), percobaan desain (desain experiment) dan analisis retropektif (retrospective analysis). Subjek penelitian ini adalah 32 orang siswa Sekolah dasar Negeri 249 Palembang. Adapun aktivitas yang dilakukan pada penelitian ini dimulai dari kegiatan lomba lari estafet, membuat tongkat e stafet dari bahan kertas berwarna, dan melakukan lompatan dengan jarak 0 dan 1 pada garis bilangan. Hasil dari penelitian ini menunjukkan bahwa konteks lomba lari estafet dapat mendukung pemahaman siswa terhadap konsep perkalian. Aktivitas-aktivitas pembelajaran yang dilakukan siswa menghasilkan lintasan belajar siswa memiliki peranan penting dalam memahami konsep perkalian dari tahap informal ke formal.

Kata Kunci: Design research, perkalian, lomba lari estafet.

Copyright (c) 2021 Sunedi

$\triangle$ Corresponding author: Sunedi

Email Address: sunedi.sudarman@gmail.com (Jl.Jend. A. Yani. Lrg. Gotoroyong 13 Ulu, Indonesia)

Received 11 Januari 2021, Accepted 03 Februari 2021, Published 03 Februari 2021

\section{PENDAHULUAN}

Konteks merupakan sebuah situasi dimana pada situasi tersebut dapat dilekatkan suatu permasalahan dan pada situasi tersebut juga dapat informasi-informasi yang dapat dijadikan solusi terhadap permasalahan tersebut (Zinov'ev \& Sole, 2003). Tujuan penggunaan konteks adalah untuk menopang terlaksananya proses guided reinvention (pembentukan model, konsep, aplikasi dan mempraktekan keahlian tertentu) dan memudahkan siswa untuk mengenali masalah sebelum memecahkannya (Zulkardi \& Ilma, 2006). Jika kita hubungkan situasi tersebut dengan perhelatan olahraga Asian Games, maka akan banyak sekali konteks yang didapatkan dari cabang-cabang olahraga yang diperlombakan khususnya cabang atletik yaitu lari estafet. 
Cabang atletik sudah diajarkan pada jenjang sekolah dasar. Ruang lingkup pembelajaran mata pelajaran jasmani olahraga dan kesehatan bermuara pada cabang atletik (Djumidar, 2004). Di dalam SK Menteri Pendidikan dan Kebudayaan Nomor: 0413/U/1987 disebutkan bahwa atletik adalah cabang olahraga yang wajib diberikan di semua jenjang pendidikan karena atletik adalah ibu dari semua cabang olahraga, sehingga atletik penting sejak anak-anak usia dini. Nomor-nomor yang dilombakan sama yaitu jalan, lari, lompat dan lempar (Bahagia, 2011). Cabang lomba lari yang dilakukan siswa SD yaitu lari jarak pendek, jarak menengah, jarak jauh dan lari esatafet. Lomba lari estafet disenangi siswa karena memerlukan kerjasama tim dengan melakukan perpidahan tongkat estafet dengan cara bersambung.

Situasi inilah dapat dimanfaatkan guru dalam proses pembelajaran matematika pada materi perkalian mengunakan konteks lomba lari estafet sebagai titik awal pembelajaran. Menurut Arisadi (2014) perkalian diartikan sebagai penjumlahan berulang. Secara matematika yang dimaksud sengan perkalian adalah penjumlahan berulang dari bilangan-bilangan yang sama pada setiap sukunya (Raharjo, 2009) Sehingga untuk memahami konsep perkalian, siswa harus paham dan terampil melakukan operasi penjumlahan. Perkalian $a \times b$ diartikan sebagai penjumlahan bilangan $b$ sebanyak $a$ kali. Sumayeka (2011) Perkalian merupakan konsep dasar yang mendukung konsep matematika seperti: pembagian, pecahan, dan persen. Ini menunjukan pentingnya kemampuan perkalian diberikan sejak kelas II SD sebagai pengetahuan dasar siswa memghadapi pembelajaran matematika tingkat lanjut.

Pembelajaran perkalian pun tidak luput dari cara tradisional, yaitu siswa menghapal tabel perkalian di depan kelas (Marga, 2013). Pembelajaran yang seperti itu hanya membuat siswa mengetahui hasil perkalian di luar kepala dari pada memahami konsep perkalian. Braddrock (2010) menyatakan bahwa pengenalan operasi perkalian seharusnya dimulai dengan situasi dari kehidupan nyata. Sehingga siswa dapat membuat model dengan memanipulasi dan menghitung semua objek yang diberikan.

Berdasarkan penelitian Sari (2013) sebagian besar anak-anak SD masih sulit membayangkan konsep abstrak karena anak SD masih berada pada tingkatan berpikir konkrit. Sudah selayaknya guru harus inisiatif dalam menerapkan dan mengembangkan bahan ajar matematika dengan berbagai cara sesuai dengan tingkat berpikir anak seusia SD.

Piaget (Hudoyo, 1998) berpendapat bahwa taraf berpikir siswa seusia SD adalah masih konkrit operasional, artinya untuk memahami suatu konsep anak masih harus diberikan kegiatan yang berhubungan dengan benda nyata atau kejadian nyata yang dapat diterima akal mereka. Sembiring (2010) mendefinisikan dunia nyata sebagai suatu dunia yang konkrit, yang disampaikan kepada siswa melalui aplikasi matematika. Oleh karena itu, siswa seharusnya terlibat dalam eksplorasi matematika dan harus diberikan kesempatan untuk menemukan kembali konsep matematika yang dipelajari menggunakan penugasan secara terbimbing dari guru sehingga pada akhirnya matematika tidak hanya diajarkan kepada siswa berupa produk yang sudah siap pakai (Zabeta, 2015). 
Pembelajaran PMRI menyesuaikan konteks yang terjadi di Indonesia (Zulkardi, 2002). Maka dari itu konteks yang dipakai dalam pembelajaran PMRI diusahakan agar berupa konteks yang pernah dialami siswa ataupun dapat dibayangkan dalam pikiran siswa.

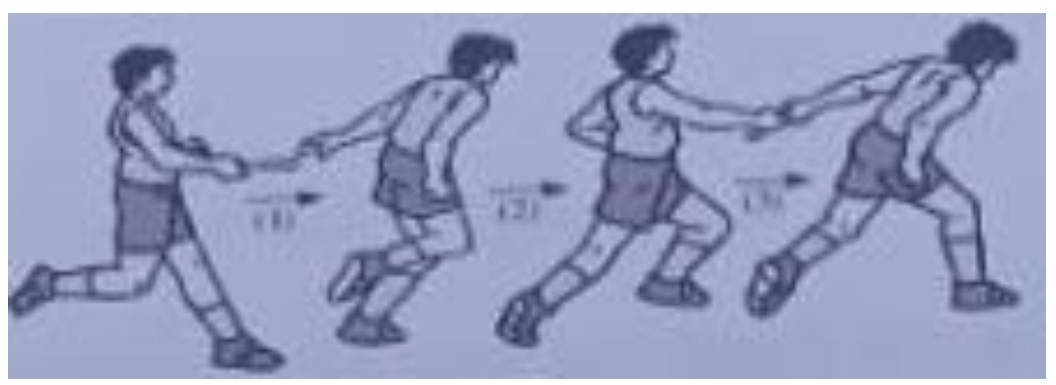

Gambar 1. Lomba lari estafet

Penelitian ini menggunakan konteks lomba lari estafet dengan nomor $4 \times 10$ meter. Karna lomba lari estafet yang dapat digunakan oleh siswa untuk mendapatkan pengalaman belajar dalam mendapatkan pemahaman yang menstimulus siswa untuk mendorong memahami konsep perkalian. Sehigga lomba lari estafet diaplikasikan sebagai aktivitas siswa yang menggali pengetahuan yang mereka miliki. Siswa secara aktif dibimbing untuk mengkonstruk pengetahuan siswa sampai terbentuk konsep perkalian.

\section{METODE}

Metode penelitian adalah metode design research sebagai cara untuk menjawab rumusan masalah sehingga tercapailah tujuan penelitian. Design research adalah suatu metode penelitian yang bertujuan untuk mengembangkan teori instruksional lokal atau local instruction theory melalui kerjasama peneliti dengan guru untuk meningkatkan kualitas pembelajaran (Gravemeijer \& Van Eerde, 2009). Dalam penelitian ini akan didesain aktivitas yang berdasarkan pengalaman siswa yaitu aktivitas yang akrab bagi siswa kelas II SD sebagai suatu pendekatan untuk memahami konsep perkalian.

Ada 3 tahap dalam design research yaitu preliminary design, teaching experiment, dan retrospective analysis (Gravemeijer, 2004). Tahap pertama preliminary design (persiapan untuk penelitian/ desain pendahuluan). Pada tahap ini dilakukan suatu kajian literatur mengenai materi perkalian, pendidikan matematika realistik dan metode design research sebagai dasar perumusan dugaan strategi awal siswa dalam pembelajaran atau sebagai landasan dalam mendesain lintasan belajar. Selanjutnya akan didesain Hypothectical learning trajectory (HLT). HLT terdiri dari tiga komponen, yaitu tujuan pembelajaran bagi siswa, aktivitas pembelajaran dan dugaan (konjektur) proses pembelajaran bagaimana mengantisipasi pemikiran pemikiran dan pemahaman siswa yang muncul ketika aktivitas pembelajaran dilakukan di kelas (Bakker, 2004). Hipotesis lintasan belajar ini dikembangkan berdasarkan literatur dan disesuaikan dengan pembelajaran yang sebenarnya selama percobaan mengajar (teaching experiment). 
Tahap kedua teaching experiment, Pada tahap kedua ini mengujicobakan kegiatan pengajaran yang telah didesain pada tahap pertama di kelas. Ujicoba ini bertujuan untuk mengeksplorasi dan menghipotesa starategi dan pemikiran siswa selama dalam proses pembelajaran. Selama prose berjalan, konjektur dapat dimodifikasi sebagai revisi dari local instructional theory untuk aktivitas berikutnya. Guru bertindak sebagai pengajar dan peneliti sebagai fokus mengamati setiap aktivitas dan momen-momen penting selama proses uji coba tersebut. Pada tahap ini sederetan aktivitas pembelajaran dilakukan lalu peneliti mengobservasi dan menganalisa apa-apa yang terjadi selama proses pembelajaran yang berlangsung di kelas.

Tahap ketiga Retrospective analysis. Pada tahap ini, data yang diperoleh dari tahap teaching experiment dianalisis dan hasil analisis ini digunakan untuk merencanakan kegiatan dan mengembangkan rancangan kegiatan pada pembelajaran berikutnya. Tujuan dari retrospective analysis secara umum adalah untuk mengembangkan local instuctional theory (LIT). Pada tahap iniHLT dibandingkan dengan pembelajaran siswa yang sebenarnya, hasilnya digunakan untuk menjawab rumusan masalah.

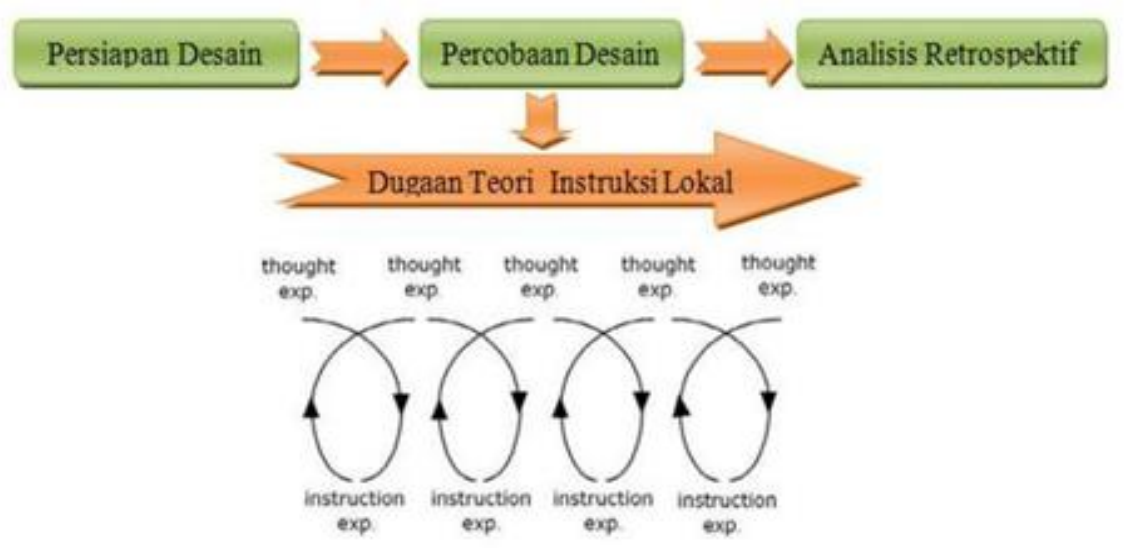

Gambar 2. Siklik Design Research (Gravemeijer, 2004)

Penelitian ini telah dilakukan pada semester genap tahun akademik 2015/2016. Subjek yang telah dilibatkan dalam penelitian ini adalah siswa kelas II SD Negeri 249 Palembang. Adapun teknik pengumpulan data dalam penelitian ini adalah rekaman video, catatan lapangan, observasi, dan dokumentasi.

\section{HASIL DAN DISKUS}

Pembelajaran yang dilakukan pada penelitian ini yaitu melalui aktivitas - aktivitas yang didesain menggunakan konteks lomba lari estafet untuk membantu siswa dalam pemahaman konsep perkalian. Pembelajaran ini bertujuaan untuk memahami konsep perkalian melalui aktivitas yang dilakukan untuk menjadikan siswa tidak mengalami kesulitan dalam memahami materi perkalian. Berikut ini deskripsi dari aktivitas-aktivitas tersebut: 


\section{Aktivitas 1: Eksplorasi Pengetahuan Awal Siswa Mengenai Lomba Lari Estafet dan Kaitannya dengan Konsep Perkalian}

Guru membentuk siswa dalam kelompok belajar yang terdiri dari 4 orang siswa dalam 1 kelompok. Secara kelompok siswa diberikan Lembar Aktivitas Siswa (LAS). Kemudian guru mengajak semua siswa kelas II tersebut untuk melakukan lomba lari estafet di halaman sekolah berdasarkan kelompoknya. Adapun jarak yang digunakan pada lomba lari estafet tersebut adalah $4 \times 10$ meter. Guru yang membimbing dalam melakukan permaian lomba lari estafet adalah guru olehraga dan dibantuh oleh guru model dan peneliti. Siswa terlihat antusias melakukan permainan lomba lari estafet dan berusaha untuk menjadi yang tercepat agar menjadi juara.

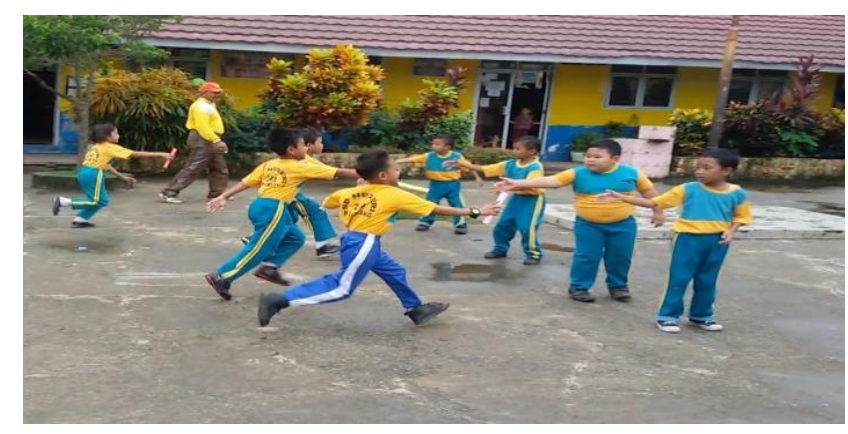

Gambar 3. Aktivitas siswa melakukan lomba lari estafet

Setelah lomba lari estafet selesai dilakukan guru mengajak siswa kembali ke dalam kelas. Guru menggiring siswa menuju konteks lomba lari estafet dengan perkalian. Selanjutnya siswa diminta untuk menjawab soal yang ada pada LAS 1 dengan berdiskusi secara berkelompok untuk mencapai konsep perkalian. Kelompok 6 yaitu Viki, Maliki, Aldila dan Salman bisa menjawab bahwa ada 4 pelari dalam satu tim, ketika ditanya berapa jarak yang ditempuh oleh satu pelari, siswa menjawab 10 meter bedasarkan lintasan lomba yang telah meraka amati. Kemudian mereka menjawab soal nomer 4 yaitu bagaimana cara menjumlahkannya semua jarak tersebut, Maliki menjawab 10+10+10+10. Ketika ditanya dari manakah mereka bisa menjumlakan seperti itu, Salman menjawab melihat dari lintasan lari yang dilakukan. Kelompok 6 sudah bisa menggunakan penjumlahan berulang ini artinya mereka memahamai maksud dari soal tersebut.

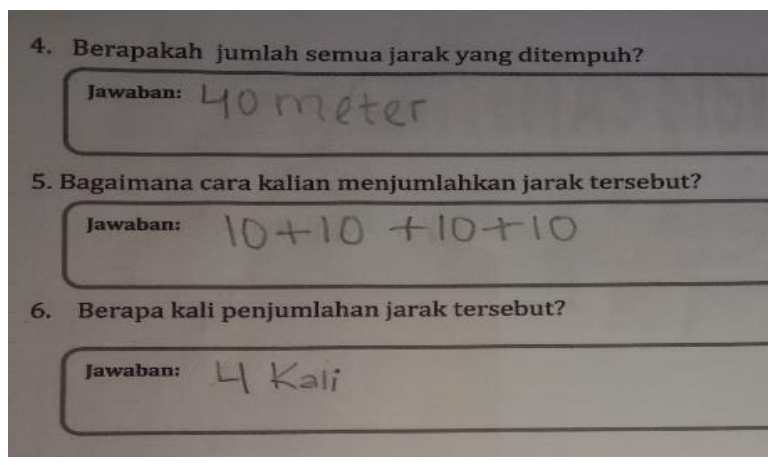

Gambar 4. Jawaban Siswa pada LAS 1 
Namun masih ada siswa yang keliruan dalam nenjawab soal pada LAS 1. Kekeliruan itu dibahas melalui tanya jawab pada saat persentasi yang dilakukan didepan kelas. Setelah tanya jawab, beberapa siswa menyadari letak kesalahannya.

\section{Aktivitas 2: Menghitung Banyak Tongkat Estafet yang Terbuat dari Kertas berwarna untuk setiap pengelompokan.}

Aktivitas 2 dilaksanakan pada pertemuan kedua, siswa membuat tongkat estafet dari bahan kertas dengan macam-macam warna dengan jumlah yang sama dalam satu ikat karet gelang yang telah disediakan. Kemudian menjawab beberapa soal yang ada pada LAS 2. Ada siswa yang menghitung satu per satu, yaitu, 1,2,3,4,5, ... 9, seperti yang dilakukan kelompok 5, yaitu Egi, Dwi, Dian dan Khamirah. Cara yang digunakan adalah menghitung langsung pada objeknya. Berikut percakapan antara peneliti dan kelompok 5 tersebut.

\begin{tabular}{|c|c|}
\hline Siswa & $\begin{array}{l}\text { : "Pak soal nomor } 2 \text { ini dihitung } \\
\text { ya?" }\end{array}$ \\
\hline Peneliti & $\begin{array}{l}\text { : "Coba bacakan pertanyaan soal } \\
\text { nomor } 2 ? "\end{array}$ \\
\hline Dwi & $\begin{array}{l}\text { :"Berapakah banyak semua } \\
\text { tongkat estafet yang dibuat?" }\end{array}$ \\
\hline Peneliti & $\begin{array}{l}\text { : "berapa jadi semua tongkat } \\
\text { estafet yang telah kalian buat?" }\end{array}$ \\
\hline Dwi & : "9 pak" \\
\hline Peneliti & $\begin{array}{l}\text { : "bagaimna kalian bisa tahu } \\
\text { bahwa itu ada 9”? }\end{array}$ \\
\hline Dian & $\begin{array}{l}\text { : "Dengan menghitungnya" } \\
\text { (Menghitung tongkat estafet) }\end{array}$ \\
\hline Peneliti & : caranya?" \\
\hline Dian & $\begin{array}{l}: \text { “ } 1,2,3,4,5,6,7,8,9 ” \\
\text { (Sembilan) }\end{array}$ \\
\hline Dwi & : "Sembilan" \\
\hline Peneliti & $\begin{array}{l}\text { : "Jadi berapa semua tongkat } \\
\text { estafet tersebut? }\end{array}$ \\
\hline Siswa & : “9 pak" (kelompok 6) \\
\hline Peneliti & $\begin{array}{l}\text { : "Khamirah berap semua tongkat } \\
\text { estafetnya?" (peneliti bertanya) }\end{array}$ \\
\hline Khamirah & :"9 pak" \\
\hline
\end{tabular}

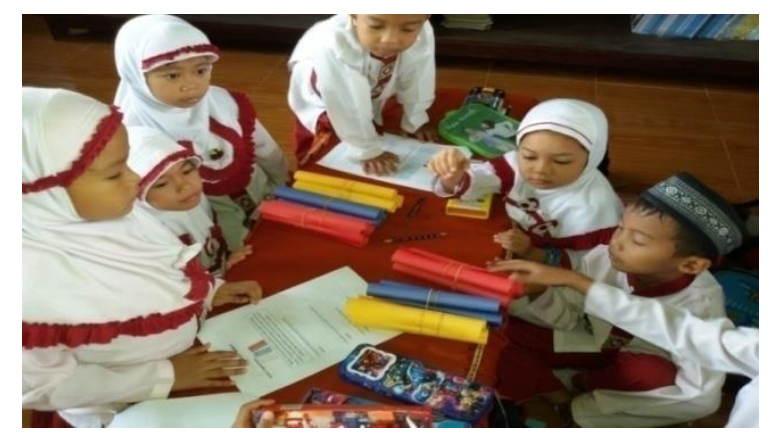

Gambar 5. Aktivitas siswa pada LAS 2 
Namun ada beberapa kelompok yang menjawab soal nomor 3 menggunakan strategi penjumlahan berulang yaitu dengan cara langsung menjumlahkan $3+3+3$ sehingga untuk mengerjakan soal nomer 4 mereka bisa menjawab dengan benar yaitu 3 kali penjumlahan tongkat estafet. Berikut percakapan peneliti dengan siswa.

\begin{tabular}{|c|c|}
\hline Peneliti & $\begin{array}{l}\text { : "Bagaimana cara kalia } \\
\text { menghitung soal nomor 3?” }\end{array}$ \\
\hline Siswa & $\begin{array}{l}\text { : "Dengan menjumlahkannya } \\
\text { secara kelompok pak, } 3 \text { merah } \\
\text { ditambah } 3 \text { kuning ditambah } 3 \\
\text { biru”" }\end{array}$ \\
\hline Peneliti & $\begin{array}{l}\text { : "Jadi bagaimana cara } \\
\text { menjumlahkannya? }\end{array}$ \\
\hline Aldila & $: " 3+3+3=9 "$ \\
\hline Peneliti & $\begin{array}{l}\text { : "Kalau soal nomor 4, bagaimana } \\
\text { kalian menjawabnya? }\end{array}$ \\
\hline Aldila & : “3 kali penjumlahan 3 pak” \\
\hline Penliti & $\begin{array}{l}\text { :"Yang lain berapa kali } \\
\text { penjumlahan? }\end{array}$ \\
\hline Viki & : “3 kali pak. \\
\hline Penliti & $\begin{array}{l}\text { : "Bagaimana menuliskannya } \\
\text { dalam bentuk perkalian" }\end{array}$ \\
\hline Aldila & : "3 $x 3 p a k "$ \\
\hline
\end{tabular}

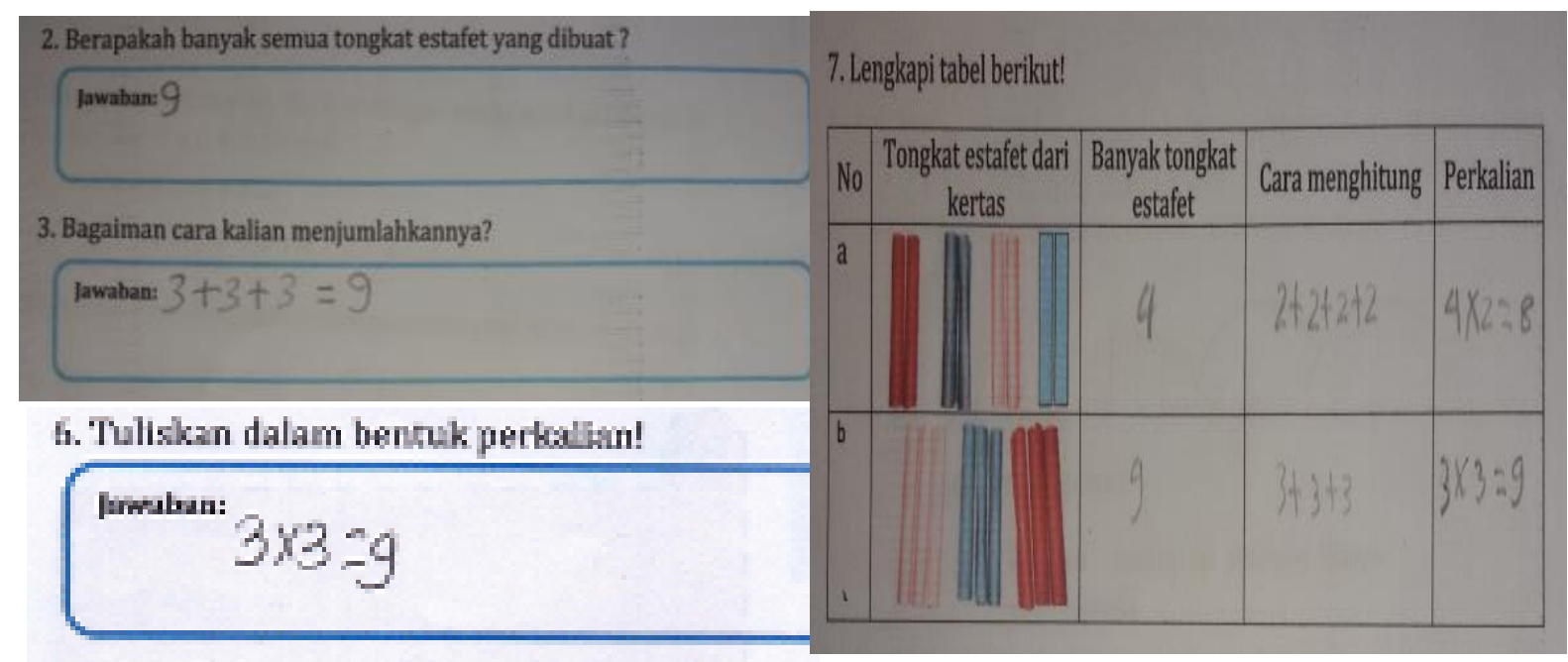

Gambar 6. Jawaban Siswa pada LAS 2

Dari keseluruan pada aktivitas 2 ini, dapat disimpulkan bahwa siswa dapat mengeksplorasi tentang konsep perkalian sebagai penjumlahan berulang. Pada tahap ini, strategi pemikiran siswa memahami konsep perkalian telah jelas dan dimengerti siswa.

\section{Aktivitas 3: Melakukan Lompatan dengan jarak 0 dan 1 pada Garis Bilangan}

Tujuan pembelajaran pada aktivitas 3 adalah siswa dapat memahami fakta perkalian 1 dan perkalian 0. Aktivitas pembelajaran yang akan dilakukan yaitu belajar perkalian melalui bermain 
lompatan pada garis bilangan. Guru meminta viki untuk bermain lompatan dengan jarak 0 pada garis bilangan yang telah disediahkan. Viki berdiri diposisi 0. Kemudian guru meminta Viki melompat dengan jarak 0. Viki binggung bagaimana lompatan dengan jarak 0. Guru bertanya kepada siswa bagaimana jika melompat dengan jarak nol (0) ?. Liona langsung menjawab "tidak melompat". Rasyid menjawab melompat tetapi tetap disanalah (ditempat). Kemudian guru bertanya dimana posisi Viki jika melompat sebanyak 3 kali. Raysid melompat 3 kali di temapat itulah. Hal ini menunjukan ada beberapa siswa yang mergerti maksut lompatan dengan jarak 0. Kemudian guru meminta siswa menjawab soal 1 dan 2 pada LAS 3. Soal nomor 2a beberapa siswa bisa menentukan perkalian dengan benar. Ada 2 kelompok yang menjawab hasilnya saja pada tabel yaitu 0 .

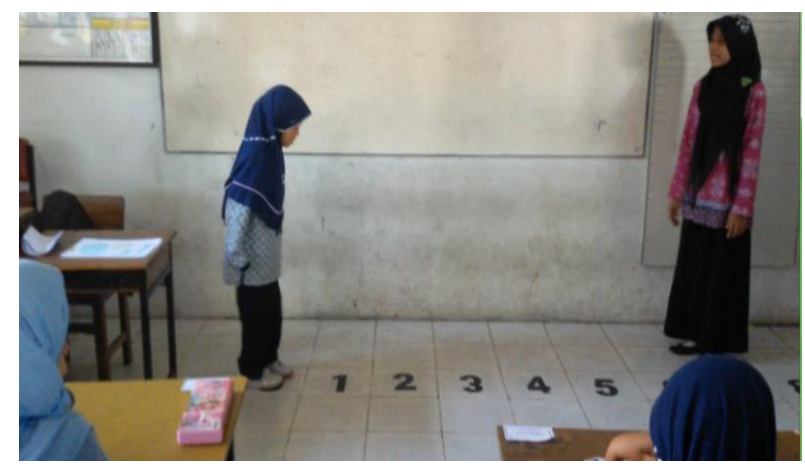

Gambar 7. Aktivitas Siswa bermain lompatan dengan jarak 0 dan 1

Ketika peneliti menggali potensi salah satu siswa (Rasyid) mengenai perkalian 0, Rasyid mampu mengungkapkan bahwa hasil perkalian 0 dan selalu 0 yang dapat dilihat melalui percakapan berikut.

$\begin{array}{ll}\text { Peneliti } & \text { : "kalau perkalian } 0 \text { itu hasilnya } \\ & \text { berapa?" } \\ \text { Rasyid } & \text { : "Nol" } \\ \text { Peneliti } & \text { : "Kalau } 5 x 0 ? \text { ?" } \\ \text { Rasyid } & \text { : "No"l } \\ \text { Peneliti } & \text { : "50x0?" } \\ \text { Rasyid } & \text { : "Nol" } \\ \text { Peneliti } & \text { : "Semua bilangan yang dikalikan } \\ & \text { dengan } 0 \text { hasilnya?" } \\ \text { Rasyid } & \text { : "Nol" }\end{array}$

Aktivitas 2 pada LAS 3 bertujuan agar siswa menemukan sendiri fakta perkalian 1. Sama halnya pada aktivitas 1 pada LAS 3, guru melakukan hal di luar skanario yaitu meminta siswa mengilustrasikan kembali bermaian lompatan dengan jarak 1. Guru memberi pertanyaan jika jarak lompatan 1, Viki melompat sebanyak 3 kali dimana posisi Viki. Rasyid menjawab 3, karena jaraknya 1. Siswa lain memperhatikan lompatan Viki dan hasilnya benar 3. Hal tersebut juga membentuk pola pikir yang sama pada beberapa siswa mengenai perkalian dengan bilangan 1. Selanjutnya siswa mengerjakan soal 4a pada tabel perkalian 1 . 


4) a. Lengkapi tabel perkalian 1 berikut!
\begin{tabular}{|c|c|c|}
\hline $\begin{array}{c}\text { Jarak } \\
\text { Lompatan }\end{array}$ & $\begin{array}{c}\text { Banyak } \\
\text { Lompatan }\end{array}$ & Perkalian \\
\hline 1 & 4 & $1 \times 4=4$ \\
\hline 1 & 6 & $1 \times 6=6$ \\
\hline 1 & 8 & $1 \times 8=8$ \\
\hline 1 & 9 & $1 \times 9=9$ \\
\hline
\end{tabular}

Gambar 8. Jawaban siswa mengenai perkalian 1

Meskipun siswa dapat melakukan perkalian 1 dan perklaian 0 , namun siswa belum bisa menyimpulkan fakta perkalian 1 dan perkalian 0. Sehingga Guru membantuh siswa untuk menyimpulkan bahwa hasil perkalian dengan 0 adalah bilangan 0 dan hasil perkalian 1 adalah bilangan itu sendiri.

Untuk mengukur pemahaman siswa terhadapa perkalian maka dilakukan tes akhir. Tes akhir menginformasikan bahwa tidak semua siswa mencapai tujuan yang diharapkan. Sebagian siswa dapat memahami jika suatu penjumlahan berulang diubah kebentuk perkalian.
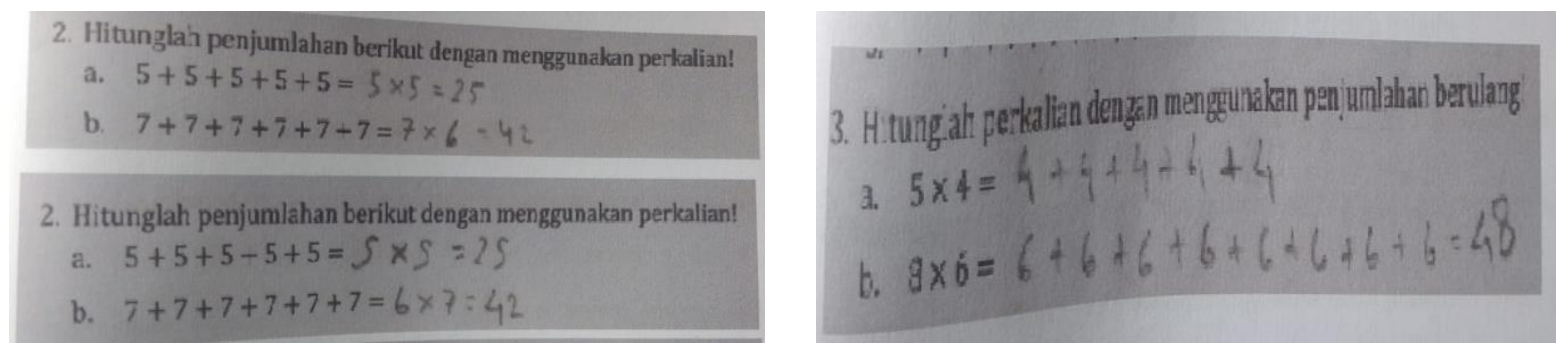

Gambar 9. Mengubah penjumlahan berulang kebentuk perkalian

Sama halnya dengan mengubah perkalian kebentuk penjumlahan berulang serta menyelesaikan soal perkalian siswa dapat menjawab dengan benar sesuai dengan yang diharapakan peneliti. Pada penelitian ini, siswa belajar perkalian melalui serangkaian aktivitas tentang materi perkalian dasar. Aktivitas-aktivitas ini disertai dengan konjektur awal peneliti terhadap pemikiran siswa, sebagai antisipasi terhadap apa yang terjadi dilapangan sehingga membantu siswa memahami makna, konsep, dan fakta perkalian serta kemampuan dalam menyelesaikan masalah kontekstual. Tidak sedikit konjektur peneliti sama dengan apa yang terjadi di lapangan. Hal tersebut seperti siswa yang belum mengenal garis bilangan, kondisi siswa yang kurang kontrol, mental siswa yang tidak percaya diri terhadap jawaban sendiri. Rancangan kegiatan, penjelasan guru, cara penyampaian materi miskomunikasi antara guru dan peneliti, dan sebagainya.

Teori pembelajaran lokal yang digunakan, yaitu Pendekatan Matematika Realistik Indonesia (PMRI). PMRI dapat diterapkan pada pembelajaran perkalian dikelas II Sekolah Dasar khususnya SD Negeri 249 Palembang. Rangkaian aktivitas pembelajaran yang dilakukan tidak terlepas dari tes awal dan tes akhir. Kedua tes tersebut tidak dibandingkan secara statistik seperti pada penelitian eksperimen. Sebaliknya, gunanya adalah untuk melihat perubahan yang berarti setelah desain pembelajaran materi perkalian melalui konteks lomba lari estafet. Walaupun soal tidak sama persis, 
dapat dilihat bahwa kemampuan yang dimiliki setiap siswa bertambah melalui proses rangkaian pembelajaran yang telah diberikan dan beberapa siswa mengalami perkembangan secara signifikan.

\section{KESIMPULAN}

Berdasarkan hasil penelitian dapat disimpulkan bahwa telah dihasilkan lintasan pembelajaran melalui tahap persiapan untuk mencoba, percobaan desain, dan analisis retrospektif. Lintasan pembelajaran materi perkalian dirancang berdasarkan pendekatan PMRI yang merupakan LIT dalam penelitian ini. Lintasan belajar melalui tahapan; (1). Lomba lari estafet, (2). Membuat tongkat estafet dari bahan kertas berwarna, dan (3). Bermain lompatan dengan jarak 0 dan 1 pada garis bilangan. Pembelajaran dimulai dari melakukan aktivitas lomba lari estafet untuk mengangkat pengetahuan awal siswa. Kemudian siswa membuat tongkat estafet dari bahan kertas berwarna dengan mengelompokannya. Pengelompokan tersebut mengarah pada penjumlahan berulang. Kemudian siswa menyelesaikan perkalian serta masalah kontekstual dengan menggunakan pengetahuan dan pengalaman sebelumnya.

\section{UCAPAN TERIMA KASIH}

Penulis mengucapakan syukur kepada Allah SWT karena telah memberikan kelancaran menyelesikan artikel ini. Terima kasih kepada guru dan siswa SD Negeri 249 Palembang sebagai tempat penelitian dilakukan serta reviewer yang telah memberikan masukan untuk perbaikan artikel ini.

\section{REFERENSI}

Arisadi. E. (2014). Meningkatkan Kemampuan Operasi Perkalian Untuk Anak Diskalkulia Melalui Metode Garismatika. Jurnal Ilmiah Pendidikan, Vol 3. Hal 478-488.

Bahagia, Y. (2011). Pembelajaran Atletik. Departemen pendidikan nasional Direktorat jenderal pendidikan dasar dan menengah. Direktorat pendidikan luar biasa.

Bakker, A. (2004). Design Research in Statistics Education on Syimbolizing and Computer Tools. Utrecht: Utrecht University.

Braddock, S. (2010). Developing Fourth Graders' Proficiency in Basic Multiplication Facts Through Strategy Instruction. B.S. University of Central Florida.

Depdiknas. (2006). Kurikulum Tingkat Satu Pendidikan Standar Kompetensi Mata Pelajaran Matematika Sekolah Dasar (SD) dan Madrasah Ibtidaiyah. Jakarta. Depdiknas

Djumidar, M. AW. (2004). Pembelajaran Atletik Untuk SD. Perpustakaan Dinas Pendidikan Pemuda dan Olahraga Kec. Madukara. Banjarnegara.

Gravemeijer, K. (2004). Local Instructional Theories as Means of Support for Teacher in Reform Mathematics Educations. Mathematical Thinking and Learning, 6(2), 105-128, Lawrence Erlbaum Association, Inc. 
Gravemeijer, K. dan Eerde, D. (2009). Design Research as a Means For Building a knowledge Base for Teaching in Mathematics Education. The Elementary School Journal, 109, (5).

Hudoyo, H. (1998). Mengajar Belajar Matematika. Jakarta: Depdikbud.

Ilma, R. (2011). Pemebelajaran Materi Bangun Datar Melalui Cerita Menggunakan Pendekatan Pendidikan Matematika Realistik Indonesia (PMRI) Sekolah Dasar. Pendidikan Matematika, FKIP Universitas Sriwijaya. Artikel JJP Malang.

Marga, A.R. (2013). Desain pembelajaran perkalian menggunakan konteks makanan khas palembang. Jurnal Pendidikan matematika, Volume 2. No.2

Raharjo, M. (2009). Pembelajaran Operasi hitung Perkalian dan pembagian bilangan cacah di SD. Yogyakarta: Pusat Pengembangan dan pemberdayaan Pendidik dan Tenaga Kependidikan (PPPPTK) Matematika.

Sari, Novita. (2013). Desain pembelajaran materi perkalian menggunakan konteks kepang karet yeye kelas II SD. Jurnal Pendidikan matematika, Volume 2. No.2

Sembiring, R.K., (2010). Pendidikan Matematika Realistik Indonesia (PMRI): Perkembangan dan tentangnya. Jurnal IndoMS. J.M.E Vol.1 No. 1 Juli 2010, pp.11-16.

Sumayeka, M. (2011). Design Research on Multiplication: Structures supporting The Development og Splitting Level at Grade in Indonesian Primary School. IndoMS. J.M.E. 199-214.

Zabeta, M., Hartono, Y., \& Putri, R. I. I. (2015). Desain Pembelajaran Materi Pecahan Menggunakan Pendekatan Pendidikan Matematika Realistik Indonesia (PMRI). Beta Jurnal Tadris Matematika, 8(1), 86-99.

Zinov'ev, D. V., \& Sole, P (2003). The Didactical Use of Models in Realistic Mathematics Education: An Example from a Longitudinal Learning Trajectory on Percentage. Educational Studies in Mathematics Journal, 54,9-35.

Zulkardi. (2002). Developing a Learning Environment on Realistic Mathematics Education for Indonesia Student Teachers. Doctoral Dissertation. Enschede: University of Twente.

Zulkardi \& Ilma, R. (2006). Mendesain Sendiri soal kontekstual Matematika. Prosiding Konferensi Nasional Matematika XIII. Semarang: IndoMS. 